ATHEROSCLEROSIS RISK FACTORS: CAN AMERICAN FAMILIES CHANGE IHEIR DIETARY HABITS AND LIFE STYLE? Hugh D. Allen, Glenn Friedman, John Gaines, Stanley J.Goldberg Univ, of Ariz.,Col of Med., Univ. Hosp., Dept. of Peds., Tucson Atherosclerosis risk factors include hypercholesterolemia, obesity, hypertension, limited exercise and smoking. To investigate the title question, we studied 199 middle class metropolitan families ( 715 people of whom $48 \%$ were children). Data were gathered concerning eating patterns, exercise, smoking, and family history. Seven hours of risk factor education were offered to participants. Six months later in 99 families ( 403 people) we obtained complete followup data concerning whether at risk subjects availed themselves of medical services. Our results (significant at $p<.05$ ) include decreases in meat (pork, beef, and lamb), eggs, butter, ice cream and salt intake. Poultry and fish intake increased. Changes include cooking fat. switched from animal to vegetable source, milk switched from whole to skim, and cheese from yellow to white varieties. There was no significant change in smokers but numbers of cigarettes decreased. Fathers became involved in regular exercise programs, but mothers did not. The only change in family history was that fathers found hypercholesterolemic relatives. Patients at risk did not avail themselves to medical services. Objective data such as serum cholesterol, blood pressures, skinfold thickness and weight all decreased significantly.

We conclude that minor education endeavors can result in significant changes in living and dietary patterns in families.

MOTHER TRAINING AS A MEANS OF ACCELERATING CHILDHOOD DEVELOPMENT IN A HIGH RISK PÓPULATION: Earladeen Badger, James Sutherland, Univ. of Cinti. CoI. of Med., Dept. of Ped.. Cincinnati, ohio.

Most preschool programs for disadvantaged have produced transitory IQ gains. However, mother training programs in Illinois have demonstrated that high risk families can intervene in their own behalf to produce more stable developmental gains. To confirm these findings and probe advantages of even earlier training, a program was begun in Jan. 1973. Groups of 12 mother/infant dyads were recruited on the postpartum unit at the Cincinnati General Hospital; infants were first-born, mature, and had high Apgar scores. Groups were matched for race and sex. $A$ group of mothers less than 16 and another more than 18 attended weekly classes in the pediatric clinic from one month following birth. Two similar groups were visited at home by an interested visitor who did not instruct. At 6 months of age early progress was assessed by Uzgiris-Hunt ordinal Scales. Analysis of variance of weighted scores indicated that infants of mothers attending classes performed significantly better than infants in the other groups $(p<.01)$. This difference was greater among children of young mothers $(p<.005)$. This is the first demonstration of active acceleration of development during the first year of life.

A COMPARISON OF THE PEDIATRIC EFHECTIVENESS OF THE BRAZEITON NEONATAL ASSESSMENT TO A STANDARD NEUROLOGICAI EXAMINATION

T. Berry Brazelton, Edward C. Tronick (Intr. by Charles A. Janeway), Harvard University Medical School, The Children's Hospital Medical Center, Dept. of Ped., Boston, Mass.

To test the clinical significance of the Brazelton Neonatal Examination, we compared its predictive value to that of a standard neurological examination. The Brazelton Assessment tests and documents the infant's organized responses to environmental events (social and non-social) and his use of "state" behavior as an organizing process in the neonatal period. The Assessment tests for neurological integrity as well as for individual differences in behaviors which may reflect future cognitive and affective competence. The subjects were a group of 53 infants judged to be suspect by pediatric examination. All the infants were given two neurological and two Brazelton examinations during the neonatal period and then followed for seven years. However, the neurological misdiagnosed three times as many normal infants as compared to the Brazelton. This greater discriminating capacity of the Brazelton examination avoids the problems entailed in misdiagnoses for parents and child, and allows for a more effective focusing of our clinical skills.
DERMATOGLYPHIC ANALYSIS OF CHILDREN WITH LEARNING PROBLEMS. Donald C. Burns and Ira S. Salafsky (Intr. by Henry L. Nadler) Northwestern Univ. Med. Sch., Evanston Hospita1, Dept. of Pediatrics, Evanston, IIl.

Dermatoglyphic patterns can only be altered by environmental factors during the lst and early 2nd trimesters. Since learning disabilities (L.D.) can have a prenatal etiology, it is likely that children with L.D. would have a greater frequency of abnormal dermatoglyphic patterns. In contrast to the children with prenatal factors, those with emotional or situational problems could be expected to have normal dermatoglyphics. Dermatoglyphic analyses were performed on 49 males and 27 females referred to our Evaluation Center for Learning Problems. Numerous dermatoglyphic parameters were studied, and, including the following, the frequency of specific patterns in children with learning problems was significantly greater than the frequency of these patterns in controls.

\begin{tabular}{lllll} 
& Palmar axial tri- & Bilatera1 \\
& radius in $t^{\prime \prime}$ & position & D-line exit \\
\hline Controls & Left & $1.9 \%$ & Males & $5.2 \%$ \\
& Right & $2.3 \%$ & Females & $8.4 \%$ \\
\hline Study group & Left & $7.9 \%(<.001)$ & Males & $26.5 \%(<.001)$ \\
& Right & $17.1 \%(<.001)$ & Females & $40.7 \%(<.001)$ \\
\hline
\end{tabular}

(number in parentheses $=$ p value determined by $\mathrm{x}^{2}$ method)

Cildren with emotional or situational problems had normal dermatoglyphics. Dermatoglyphics may be useful in recognizing children whose L.D. has a prenatal etiology.

THE LONG TERM NEUROLOGICAL SEQUELAE OF ANEMIA IN INFANCY Ronald J. Cantwell (Intr. by William W. Cleveland) Univ. of Miami Sch. of Med. Dept. of Ped. Mlami, Florida.

To determine if hypoxemia from anemia in infancy causes brain damage, 61 full term infants from comparable socioeconomic groups were studied developmentally from birth to 7 years Thirty-two of the infants developed iron deficiency anemia between 6-18 months of age (Hgb range 6.1-9.5 G\%) in the absence of protein calorie malnutrition. Twenty-nine infants received neonatal iron dextran injections and were not anemic (Hgb range $11.5-12.9 \mathrm{G} \%$ ).

Neurological evaluation was done at 6-7 years of age without knowledge of the presence or absence of prior anemia. Each test was rated on a $0-3$ scale or by stanines. The group formerly anemic had a higher incidence of "soft signs" e.g. clumsiness with balancing on one foot, in tandem walking, and repetitive hand or foot movements, etc. and were more inattentive and hyperactive than the non anemic group. Binet IQ scores averaged 98 in the non anemic and 92 in the anemic group. Anemia in infancy appears to be one cause of minimal brain dysfunction which may be permanent.

\section{CHILDHOOD LEUKEMIA AND MATERNAL INFECTIONS DURING} PREGNANCY

Mary G. McCrea Curnen, Andre Varma, Barbara Chxistine, *

and Livia Turgeon. (Intr. by Edward C. Curnen, Jr.)

Columbia University College of Physicians \& Surgeons

School of Public Health, New York

The Connecticut Tumor Registry has records of 431 children who developed leukemia during their first ten years of life and who were born in Connecticut. These children were grouped into 27 annual birth cohorts for the years 1935 through 1961 .

Time/space clustering was studied by various statistical methods using the date and place of residence at birth.

The hypothesis that children born of women pregnant during epidemics of infectious diseases are at a higher risk of developing leukemia was tested extensively.

Evidence was sought for a relation between the occurrence of influenza, chickenpox, measles, German measles, mumps, poliomyelitis and whooping cough during pregnancy and leukemia in the offspring. No significant positive correlations were found.

*State of Connecticut Department of Health, Chronic Disease Control Section, Connecticut Tumor Registry, Hartford 